Article

\title{
Day-Ahead Dispatch Model of Electro-Thermal Integrated Energy System with Power to Gas Function
}

\author{
Deyou Yang (D), Yufei Xi * and Guowei Cai \\ School of Electrical Engineering, Northeast Electric Power University, Jilin 132012, China; \\ eedyyang@hotmail.com (D.Y.); caigw@nedu.edu.cn (G.C.) \\ * Correspondence: xyfneepu@outlook.com; Tel.: +86-432-6480-6691
}

Received: 28 October 2017; Accepted: 14 December 2017; Published: 20 December 2017

\begin{abstract}
The application of power to gas (P2G) provides a new way to absorb intermittent renewable energy generation, which improves the efficiency of renewable energy utilization and provides the necessary flexibility for operating the integrated energy system. The electro-thermal integrated energy system with P2G is a new form of using energy efficiently. In this paper, we first introduce the technology and application of P2G. On the basis of considering the characteristics of P2G facilities, power systems, natural gas systems and heating systems, an optimal dispatching model of electro-thermal multi-energy system with P2G facilities is proposed. Particle swarm optimization is used to solve the optimal scheduling model. The simulation results are discussed for the six-bus and six-node integration system and show that when the volume fraction of hydrogen does not exceed $20 \%$ in the gas network, for the same operating mode, an integrated energy grid with P2G function will save about 20 tons of standard coal per day and the abandoned wind rate can be regarded as 0 .
\end{abstract}

Keywords: power to gas; hydrogen storage; wind power; HCNG; combined heat and power

\section{Introduction}

With new energy utilization receiving widespread attention, the installed capacity of photovoltaic $(\mathrm{PV})$, wind power and other new energy generation system are increasing [1-3]. It is expected that the installed wind capacity will reach 200 million $\mathrm{kW}$ by 2020. However, wind power utilization is often limited due to the unsynchronized construction between wind farms and power grids, as well as the mismatching between wind power characteristics and peaking capability. In some areas, these "abandoned wind" phenomena directly lead to energy waste and economic losses.

A typical integrated energy system includes natural gas supply, power supply and thermal energy supply, which can increase renewable energy efficiency by means of coordinating and optimizing various energy links in the integrated system. At the same time, developing gas storage technology, power storage technology and heat storage technology in the integrated energy network to form multiple consumptive technology or multiple energy storage technology, can reduce the abandon wind or light. In view of the high cost of large power storage and the relatively low cost of gas storage, gas storage technology can be greatly developed in the integrated system. For instance, based on P2G technology the excess wind power is converted into hydrogen which is mixed with natural gas or used as a material for producing synthetic natural gas. This method will directly reduce the abandoned wind power from the production source.

P2G technology is a process of converting electrical energy into gas energy. At valley load period of power output or peak load period of renewable energy output, the excess energy is converted to hydrogen or natural gas stored in the gas storage device. In the event of an electric or heat shortage period, the stored gas transported by natural gas pipelines is converted to electrical or thermal energy to the users, which enhances the ability of the integrated energy system to absorb renewable energy 
during valley load periods. $\mathrm{P} 2 \mathrm{G}$ technology also increases the role of electro-gas coupling in the system and enhances the coupling between power systems and natural gas systems.

Scholars in various countries have carried out many explorations into P2G research. In [4], the economic potential of P2G technology is evaluated. In [5], the potential role of P2G in future energy systems is discussed. And P2G is considered as a storage system with relatively large storage capacity but relatively low efficiency (i.e., energy storage). In [6], the research aims to investigate an innovative biogas upgrading process, based on gas hydrate technology, and combine it with power-to-gas technology to produce additional synthetic methane. In [7], P2G is the way to decarbonize the energy supply chain as a fraction of Hybrid fuels, combination of fossil ones and Renewable Hydrogen, as an immediate responsive storage solution. The authors investigated different urban energy scenarios at RES share increase from $25 \%$ up to $50 \%$ in the energy mix to highlight strengths and weaknesses of the P2G applications. In [8], the researchers combine P2G with gas turbines to study the influence on abandoned wind power of the system. In [9], P2G technology is considered as energy storage form with long-term and wide area, which achieves large-scale storage and transmission of renewable energy resources. On the side of integrated energy systems, literature [10] introduces the method of modeling, planning and optimization of the regional integrated energy system. In [11], based on the uncertainty of power, gas, thermal loads and wind power, the probabilistic energy flow of integrated energy system coupled by electricity and natural gas is solved. The research work provides some theoretical principle and basis for P2G integration. At present, most of the researches have conducted in-depth analysis of the gas system, power system and thermal system separately, but the coordination analysis of the gas-electricity-thermal integrated system is still insufficient. Therefore, the P2G used in this paper can convert surplus wind power into natural gas or hydrogen and store it in natural gas pipelines during periods of low load or peak output of renewable energy, and can then provide the users with energy by converting the stored gas to electricity in the event of a shortage of electricity or thermal energy, thereby achieving the bi-directional energy conversion.

The present paper aims to investigate a scheduling strategy for integrated energy system, based on gas hydrate technology and power-to-gas technology, and at combining them with heat and power cogeneration to improve wind power consumption and utilization capacity in the integrated energy network. The electro-thermal integrated energy system with P2G Function proposed in this paper incorporates hydrogen as clean energy into existing gas supply networks, which realizes the complementary transformation of power to gas. The combined system can produce high quality power and clean secondary energy, which provides a new way to solve the problem of wind power consumption in power system. The remainder of the paper is organized as follows. In Section 2, the technology and application of P2G are introduced. In Section 3, the day-ahead dispatching model of the electro-thermal integrated energy system with P2G is proposed. In Section 4, case studies are conducted to demonstrate the benefit and effectiveness of the proposed model and method.

\section{The Concept of P2G}

\subsection{Water Electrolysis}

The chemical principle of water electrolysis technology is that the water is reduced to form hydrogen at the cathode and oxidized to form oxygen at the anode when the current through the water. The chemical formula is as follows:

$$
2 \mathrm{H}_{2} \mathrm{O} \stackrel{\text { energize }}{\rightarrow} 2 \mathrm{H}_{2}+\mathrm{O}_{2}
$$

The essence of an electrolytic cell is composed of a series of electrochemical cells containing metal poles and electrolyte. At present, there are two main technologies of water electrolysis: alkaline electrolyzer and proton exchange membrane electrolyzer. The third technology, solid oxide electrolysis has not been widely used. The structure of these electrolyzers are shown in Figure 1. 


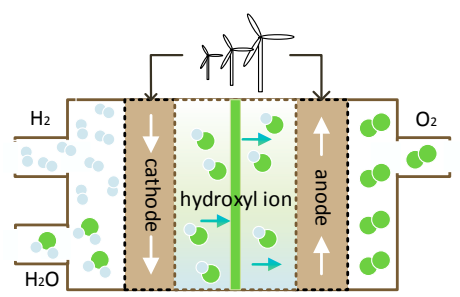

(a)

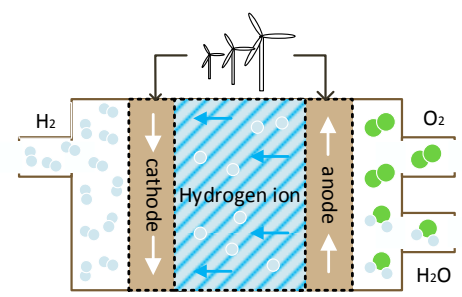

(b)

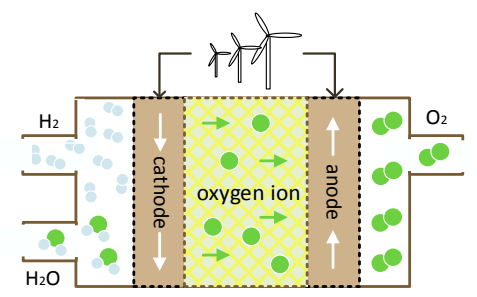

(c)

Figure 1. Diagrams of (a) alkaline electrolyzer, (b) Proton exchange membrane electrolyzer and (c) Solid oxide electrolyzer.

\subsection{Synthetic Natural Gas}

In the process of coal to natural gas, hydrogen plays an irreplaceable role. In addition to the most traditional process, methanation of coal-gas, there are steam gasification process and hygas process currently. Illustrated by the example of the hygas process, hydrogen as gasification agent and coal are converted into natural gas in the gasification unit. The simplification is expressed as follows:

$$
\mathrm{C}+2 \mathrm{H}_{2} \rightarrow \mathrm{CH}_{4} \quad \Delta \mathrm{H}=-74.8 \mathrm{~kJ} \cdot \mathrm{mol}^{-1}
$$

The process is characterized by its by-products, aromatic compounds, such as benzene, produced by the reaction of coal and Hydrogen at high temperature, whose original aim is to generate methane. Here, hydrogen as the raw material of methanation reaction will be directly involved in the preparation of natural gas as follows:

$$
\begin{aligned}
& \mathrm{CO}+3 \mathrm{H}_{2} \rightarrow \mathrm{CH}_{4}+\mathrm{H}_{2} \mathrm{O} \quad \Delta \mathrm{H}=-206.2 \mathrm{~kJ} / \mathrm{mol} \\
& 2 \mathrm{CO}+2 \mathrm{H}_{2} \rightarrow \mathrm{CH}_{4}+\mathrm{CO}_{2} \quad \Delta \mathrm{H}=-247.4 \mathrm{~kJ} / \mathrm{mol} \\
& \mathrm{CO}_{2}+4 \mathrm{H}_{2} \rightarrow \mathrm{CH}_{4}+2 \mathrm{H}_{2} \mathrm{O} \quad \Delta \mathrm{H}=-165 \mathrm{~kJ} / \mathrm{mol}
\end{aligned}
$$

With the continuous development and promotion of biogas technology, the combination of hydrogen and biogas digesters will be a major way to achieve an energy conversion of power-hydrogen to gas, when the required hydrogen can be produced in large quantities.

\section{3. $H C N G$}

HCNG, a mixture of compressed natural gas and hydrogen by energy, was studied in detail by the European project called NATURALHY in the period from June 2004 to 2009. The study shows that the natural gas pipeline not only provides a large transport channel for hydrogen, but also makes the loss of hydrogen very small in the transmission process. Moreover, the utilization of hydrogen can reach more than $90 \%$ in the pipeline terminal [12]. The Dutch study shows that the volume fraction of hydrogen mixed with natural gas can reach $12 \%$ [13]. The GRHYD project supported by the French Environment and Energy Control Agency shows that if hydrogen is supplied to the gas stations or the users, the volume fraction of mixed hydrogen will be as high as $20 \%$ [14].

The application of HCNG involves transportation fuel, civil clean gas, residential heating and so forth. The gas network as an example is mainly used for daily heating demand. If the hydrogen can be transferred by the gas network and used for heating, the consumption of natural gas will reduce on a large scale. 


\section{Electro-Thermal Integrated Energy System with “P2G Function”}

\subsection{Structure of the Integrated System}

Taking HCNG as an example, a new model for combining heat and power system with P2G function is presented. The coupling system involves three kinds of energy network including power grid, district heating network and natural gas network. The output units include wind turbines (WTs), electrolyzers, combined heat and power units (CHPs) and gas-fired boilers (GBs), as shown in Figure 2.

In the power system, the upstream grid based on the thermal units (TUs), the WTs and the CHPs supply the consumers' electricity demand. In the district heating network, the gas-fired boilers (the fuel contains the natural gas and the hydrogen from the abandoned wind power) and the CHPs supply the consumers' heat demand. In addition, the power of TUs is produced from coal, while the power of other production equipment (such as cogeneration units, gas boilers) is produced by natural gas or HCNG. In order to unify the power of the grid, these different energy consumptions will be converted into standard coal consumption to express the overall energy.

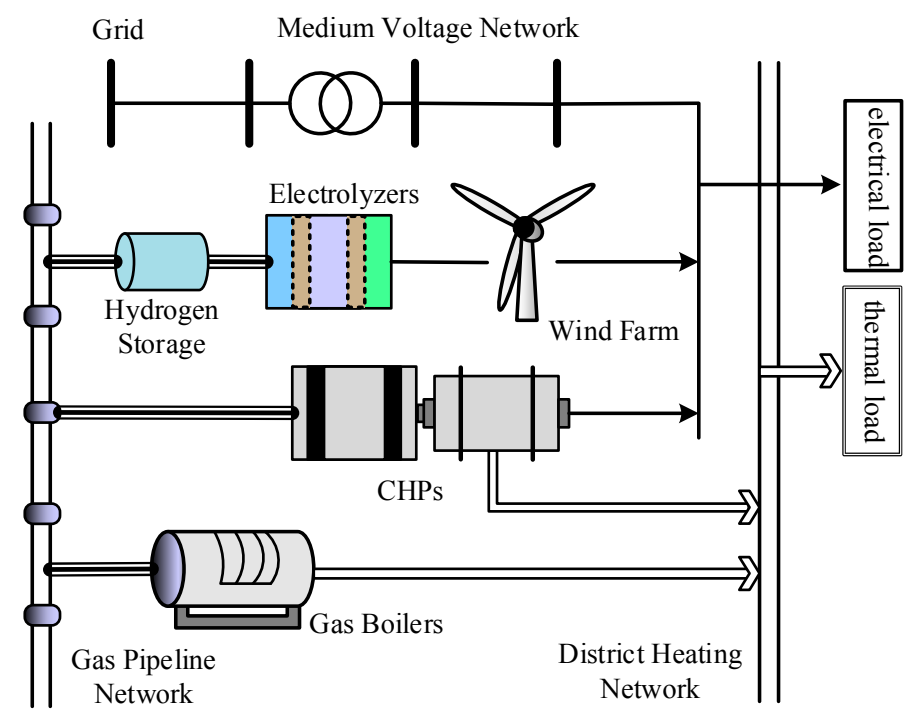

Figure 2. The architecture diagram of combined power-heat system with power to gas (P2G) function.

\subsection{Day-Ahead Dispatch Model of the Integrated System}

In order to verify the economic benefits of the interconnected system, we propose the day-ahead dispatch model of the system which is mentioned above. The parameters and functions involved in the model are shown in Table 1.

\section{(A) Objective Function}

Starting from the perspective of energy conservation, the objective of the day-ahead dispatch model is to make the integrated system have minimum standard coal consumption.

$$
\min \sum_{t=1}^{T}\left[\sum C_{i, t}^{\mathrm{TU}}\left(p_{i, t}^{\mathrm{TU}}\right)+\sum C_{i, t}^{\mathrm{CHP}}\left(p_{i, t}^{\mathrm{CHP}}, h_{i, t}^{\mathrm{CHP}}\right)+\sum C_{i, t}^{\mathrm{GB}}\left(h_{i, t}^{\mathrm{gas}}\right)\right]
$$

where $t$ is time index ( $1 \mathrm{~h}$ resolution), $T$ is the time horizon $(24 \mathrm{~h})$. Equations (7)-(9) give specific definitions respectively.

$$
\begin{gathered}
C_{i, t}^{\mathrm{TU}}\left(p_{i, t}^{\mathrm{TU}}\right)=\lambda^{\mathrm{TU}} \cdot p_{i, t}^{\mathrm{TU}} \\
C_{i, t}^{\mathrm{CHP}}\left(p_{i, t}^{\mathrm{CHP}}, h_{i, t}^{\mathrm{CHP}}\right)=\lambda_{p}^{\mathrm{CHP}} \cdot p_{i, t}^{\mathrm{CHP}}+\lambda_{h}^{\mathrm{CHP}} \cdot h_{i, t}^{\mathrm{CHP}}
\end{gathered}
$$




$$
C_{i, t}^{\mathrm{GB}}\left(h_{i, t}^{\mathrm{gas}}\right)=\lambda^{\mathrm{GB}} \cdot h_{i, t}^{\mathrm{gas}}
$$

(B) Constraint

First of all, for an urban distribution network with $I$ nodes, the optimization period is $T$. Equation (10) defines the active power flow balance.

$$
\sum p_{i, t}^{\mathrm{TU}}+\sum p_{i, t}^{\mathrm{CHP}}+\sum p_{i, t}^{\mathrm{WT}, \mathrm{gc}}=\sum p_{i, t}^{\mathrm{load}}
$$

The power output of a wind farm is limited by its available wind power:

$$
0 \leq p_{i, t}^{\mathrm{WT}, \mathrm{gc}} \leq p_{i, t}^{\mathrm{WT}, \max }
$$

If the volume fraction of hydrogen is $20 \%$, the ratio of hydrogen to natural gas should be satisfied with the inequality (12). Equation (13) defines the quantity of the hydrogen production made by the electrolyzers which is driven by the abandoned wind power.

$$
\begin{gathered}
\frac{F_{i, t}^{\mathrm{H}_{2}} \cdot \rho^{\mathrm{gas}}}{F_{i, t}^{\mathrm{gas}} \cdot \rho^{\mathrm{H}_{2}}} \leq 20 \% \\
F_{i, t}^{\mathrm{H}_{2}} \cdot t=\left(p_{i, t}^{\mathrm{WT}, \text { true }}-p_{i, t}^{\mathrm{WT}, \mathrm{gc}}\right) \cdot \eta_{F} \cdot g^{\mathrm{H}_{2}}
\end{gathered}
$$

Actually $\left(p_{i, t}^{\mathrm{WT}, \text { true }}-p_{i, t}^{\mathrm{WT}, \mathrm{gc}}\right)$ is abandoned wind power, and it is also the share of the total power production used for $\mathrm{H}_{2}$ production at period $t$. The gas boilers are using HCNG to produce heat. Equations (14) and (15) define the thermal power output of the natural gas part and the hydrogen part respectively. And Equation (16) sets the thermal generation limits.

$$
\begin{gathered}
h_{i, t}^{\mathrm{gas}}=F_{i, t}^{\mathrm{gas}} \cdot \eta^{\mathrm{GB}} \\
h_{i, t}^{\mathrm{H}_{2}}=F_{i, t}^{\mathrm{H}_{2}} \cdot \eta^{\mathrm{GB}} \\
h_{i}^{\mathrm{GB}, \min } \leq h_{i, t}^{\mathrm{gas}}+h_{i, t}^{\mathrm{H}_{2}} \leq h_{i}^{\mathrm{GB}, \max }
\end{gathered}
$$

The amount of electricity delivered by the CHPs can be adjusted within operating limits. Equation (17) defines the electrical power output. Equation (18) defines the thermal power output.

$$
\begin{aligned}
& P_{i, t}^{\mathrm{CHP}}=\frac{h_{i, t}^{\mathrm{EX}} \cdot \eta_{e}^{\mathrm{CHP}}}{\left(1-\eta_{\mathrm{e}}^{\mathrm{CHP}}-\eta_{\mathrm{L}}\right)} \\
& h_{i, t}^{\mathrm{CHP}}=h_{i, t}^{\mathrm{EX}} \cdot \eta_{\mathrm{th}}^{\mathrm{CHP}} \cdot c_{\mathrm{OPh}}
\end{aligned}
$$

Equation (19) sets the electrical generating limits. The incremental change in the generation of a $\mathrm{CHP}$ within a single period is restricted by its ramping capability as shown in Equation (20).

$$
\begin{aligned}
& p_{i}^{\mathrm{CHP}, \min } \leq p_{i, t}^{\mathrm{CHP}} \leq p_{i}^{\mathrm{CHP}, \max } \\
& -R \Delta t \leq p_{i, t}^{\mathrm{CHP}}-p_{i, t-1}^{\mathrm{CHP}} \leq R \Delta t
\end{aligned}
$$

The district heating network needs to meet the balance of supply and demand of heat. Generation is allowed to be greater than demand to give more flexibility to the problem.

$$
\sum h_{i, t}^{\text {load }}=\sum\left(h_{i, t}^{\mathrm{CHP}}+h_{i, t}^{\mathrm{GB}}\right)
$$


Table 1. Parameters and functions.

\begin{tabular}{|c|c|}
\hline Name & Definition \\
\hline$p_{i, t}^{\mathrm{TU}}$ & Generation output of thermal unit $i$ at period $t$. \\
\hline$p_{i, t}^{\mathrm{CH}}$ & Generation output of combined heat and power unit $i$ at period $t$. \\
\hline$p_{i, t}^{\mathrm{W} T, \mathrm{gc}}$ & Grid-connected output of wind turbine $i$ at period $t$. \\
\hline$h_{i, t}^{\mathrm{CHP}}$ & Heat production output of combined heat and power unit $i$ at period $t$. \\
\hline$h_{i t}^{l, k}$ & Heat production output of gas-fired boiler $i$ at period $t$. \\
\hline$h_{i, t}^{\text {gat }}$ & Natural gas part of heat production output of gas-fired boiler $i$ at period $t$. \\
\hline$h_{i, t}^{\text {hydrogen }}$ & Hydrogen part of heat production output of gas-fired boiler $i$ at period $t$. \\
\hline$C_{i, t}^{\mathrm{TU}}$ & Standard coal consumption of thermal unit $i$ at period $t$. \\
\hline$C_{i, t}^{C L}$ & Standard coal consumption of combined heat and power unit $i$ at period $t$. \\
\hline$C_{i, t}^{\mathrm{GBB}}$ & Standard coal consumption of gas-fired boiler $i$ at period $t$. \\
\hline$\lambda^{\text {T⿱t口 } U}$ & Conversion coefficient of standard coal for thermal units. \\
\hline$\lambda_{\mathrm{p}}^{\mathrm{CHP}}$ & Conversion coefficient of standard coal for the CHPs' power supply. \\
\hline$\lambda_{\mathrm{h}}^{\mathrm{CHP}}$ & Conversion coefficient of standard coal for the CHPs' heat supply. \\
\hline$\lambda^{1 \mathrm{~GB}}$ & Conversion coefficient of standard coal for gas fired boilers. \\
\hline$p_{i, t}^{\text {load }}$ & Net active load demand in node $i$ at period $t$. \\
\hline$p_{i, t}^{\mathrm{WT}, \max }$ & Maximum generation output of wind turbine $i$ at period $t$. \\
\hline$F_{i, t}^{\text {gas }}$ & Air input of natural gas at period $t$. \\
\hline$F_{i, t}^{H 2}$ & Air input of hydrogen at period $t$. \\
\hline$\rho^{\text {gas }}$ & Density of natural gas. \\
\hline$\rho^{\mathrm{H} 2}$ & Density of hydrogen. \\
\hline$\eta_{\mathrm{F}}$ & Electrolytic efficiency of electrolyzers. \\
\hline${ }_{0} \mathrm{H} 2$ & Production of hydrogen per kilowatt hour. \\
\hline$p_{i, t}^{\mathrm{WT}, \text { tru }}$ & Actual generation output of wind turbine $i$ at period $t$. \\
\hline$\eta^{\mathrm{GB}}$ & Efficiency of gas-fired boilers. \\
\hline$h_{i, t}^{\mathrm{GB}, \min } / h_{i, t}^{\mathrm{GB}, \max }$ & Maximum/minimum generation output of gas-fired boiler $i$ at period $t$. \\
\hline$p_{i}^{\mathrm{CH}, \mathrm{HP}, \min } / p_{i, t}^{\mathrm{CL}} \mathrm{HP}, \max$ & Maximum/minimum generation output of CHP $i$ at period $t$. \\
\hline$h_{i, t}^{\mathrm{EX}}$ & Residual heat of the gas displacement. \\
\hline$\eta_{\mathrm{e}}^{\mathrm{CH} H \mathrm{HP}}$ & Electrical efficiency of combined heat and power units. \\
\hline$\eta_{\mathrm{L}}$ & Cooling efficiency of combined heat and power units. \\
\hline$\eta_{\mathrm{th}}^{\mathrm{CHP}}$ & Thermal efficiency of combined heat and power units. \\
\hline$c_{\mathrm{OPh}}$ & Coefficient of performance. \\
\hline$R \Delta t$ & Ramping capability of combined heat and power units. \\
\hline
\end{tabular}

\subsection{Solution Strategy}

Similar to the genetic algorithm, particle swarm optimization (PSO) is an iterative optimization algorithm developed by Kennedy and Eberhart $[15,16]$. It is considered as realistic and powerful solution schemes to obtain the global or quasi-global optimums in power system optimization problems. Also, PSO has been successfully applied to a number of optimization problems. For the above model, the complex constraints of the nonlinear decision variables make it difficult to solve the model directly. PSO is developed in this section for the day-ahead dispatch model. The electrical decision variables including $p_{i, t}^{\mathrm{TU}}, p_{i, t}^{\mathrm{CHP}}, p_{i, t}^{\mathrm{WT}, \mathrm{gc}}$ and the thermal decision variables including $h_{i, t}^{\mathrm{CHP}}, h_{i, t}^{\mathrm{gas}}$, $h_{i, t}^{\text {hydrogen }}$ are denoted by $x$, Then the day-ahead dispatch model can be described in an abstract form:

$$
\min _{x}\{f(x) \text { : s.t.h }(x)=0, g(x) \leq 0\}
$$

where $f(x)$ denotes the objective function as shown in Equation (23), $h(x)=0$ and $g(x) \leq 0$ denote the constraints described in Equations (10)-(21).

$$
\begin{gathered}
f(x)=\sum_{t=1}^{T}\left[\sum C_{i, t}^{\mathrm{TU}}\left(p_{i, t}^{\mathrm{TU}}\right)+\sum C_{i, t}^{\mathrm{CHP}}\left(p_{i, t}^{\mathrm{CHP}}, h_{i, t}^{\mathrm{CHP}}\right)+\sum C_{i, t}^{\mathrm{GB}}\left(h_{i, t}^{\mathrm{gas}}\right)\right] \\
=\sum_{t=1}^{T}\left[\sum\left(\lambda^{\mathrm{TU}} \cdot p_{i, t}^{\mathrm{TU}}\right)+\sum\left(\lambda_{\mathrm{p}}^{\mathrm{CHP}} \cdot p_{i, t}^{\mathrm{CHP}}+\lambda_{\mathrm{h}}^{\mathrm{CHP}} \cdot h_{i, t}^{\mathrm{CHP}}\right)+\sum\left(\lambda^{\mathrm{GB}} \cdot h_{i, t}^{\mathrm{gas}}\right)\right]
\end{gathered}
$$


Take the decision variables $x=\left(x_{1}, x_{2}, \ldots, x_{n}\right)$ to be solved as $n$ particles without mass and volume. The position and velocity vectors of the $i$ th particle of a two-dimensional search space can be represented as $s_{i}=\left(s_{1}, s_{2}, \ldots, s_{n}\right)$ and $v_{i}=\left(v_{1}, v_{2}, \ldots, v_{n}\right)$ respectively, After initialization, the particle tries to modify its position using the current velocity and the distance on the basis of the value of the evaluation function. The best previous position of a particle is recorded and represented as pbest. If the $g$ th particle is the best among all particles in the group so far, it is represented as pbest $=$ gbest. Before finding its optimal value, the particle updates its velocity and position by the following equations:

$$
\begin{gathered}
v_{i, t+1}=\omega v_{i, t}+c_{1} \text { rand }_{1}\left(\text { pbest }-s_{i, t}\right)+c_{2} \text { rand }_{2}\left(\text { gbest }-s_{i, t}\right) \\
s_{i, t+1}=s_{i, t}+v_{i, t+1}
\end{gathered}
$$

where, $\omega$ is the inertia weight parameter, $c$ is constriction factor, $c_{1}$ and $c_{2}$ are cognitive and social coefficients, $r a n d_{1}, \operatorname{rand}_{2}$ are random numbers between 0 and 1 . The concept of time varying inertial weight was introduced in [17] per $\omega$ is given by

$$
\omega=\left(\omega_{\max }-\omega_{\min }\right) \cdot \frac{\left(\text { iter }_{\max }-\text { iter }\right)}{\text { iter }_{\max }}+\omega_{\min }
$$

where, iter $\max _{\text {ax }}$ is the maximum number of iterations. Usually, the parameters are selected in the range of 0 to 4 . The flowchart of the iterative algorithm is shown in Figure 3.

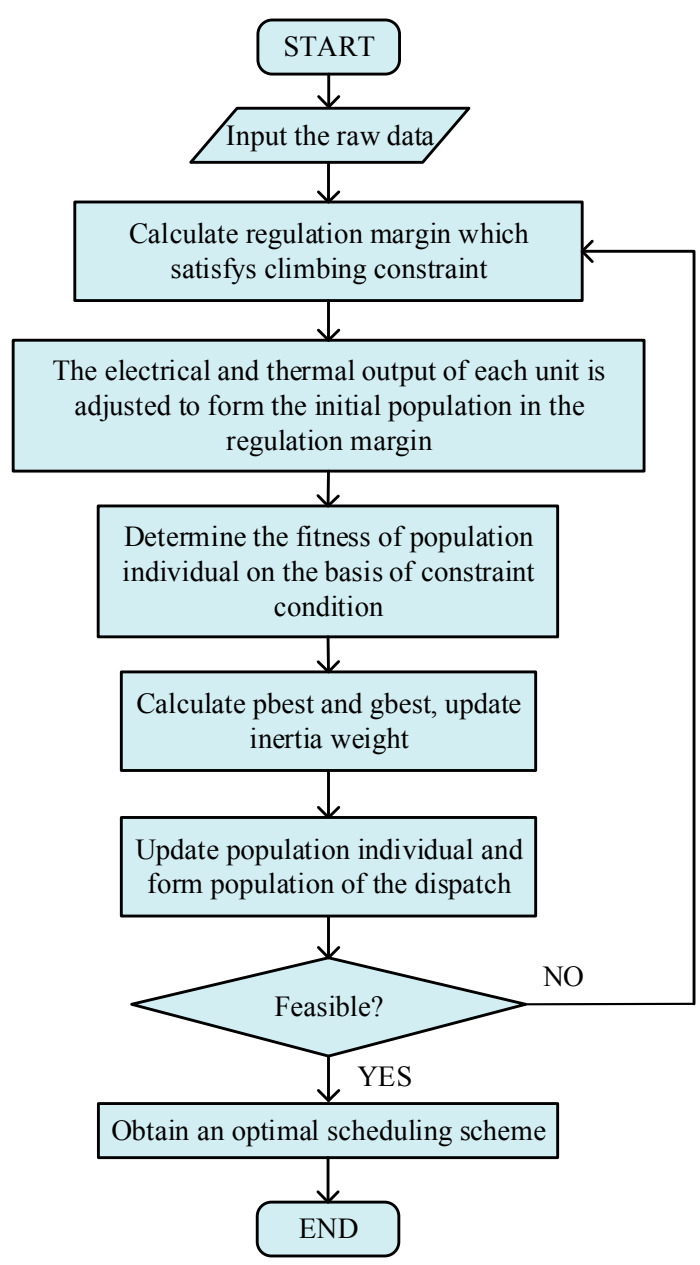

Figure 3. Flowing of solving day-ahead dispatch model with particle swarm optimization (PSO). 


\section{Simulation Results}

\subsection{Example Data}

Figure 4 shows the one-line diagram of an integrated system of a six-bus electric power system and a six-node district heating system, which is used in this study. The heat source of a district heating system is provided by a gas cogeneration unit. In comparison, in a wind farm, the electricity infrastructure has two generators at Bs1, Bs2 and Bs6. The typical output of wind power and daily electric and thermal loads are shown in Figure 5. It represents the basic trend and fluctuation of wind power output, thermal load and electrical load in a day during the winter heating period in China. It can be seen from the diagram that heat and electrical loads have opposite peaks, this is because the ambient temperature is high in the daytime and low in the nighttime. The wind power and electric loads also have opposite peaks pertaining to high wind penetration. Such settings are consistent with those of electric power systems.

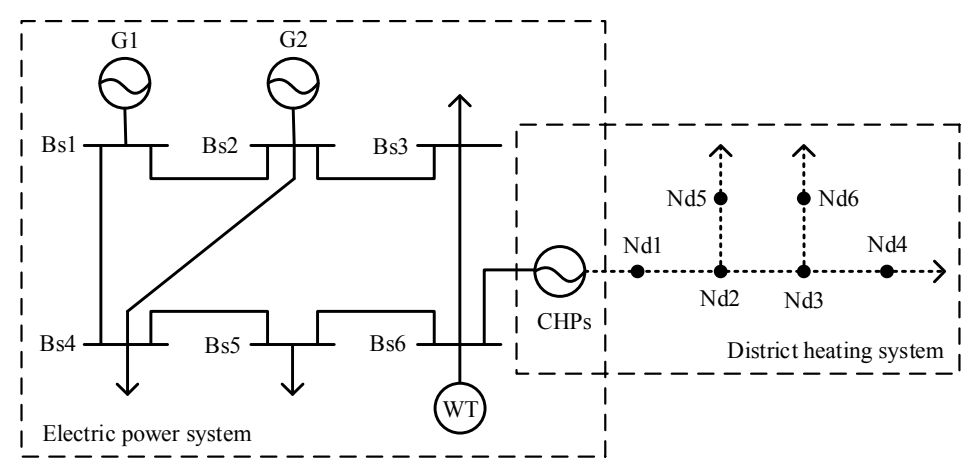

Figure 4. Configuration of the six-bus and six-node integration system.

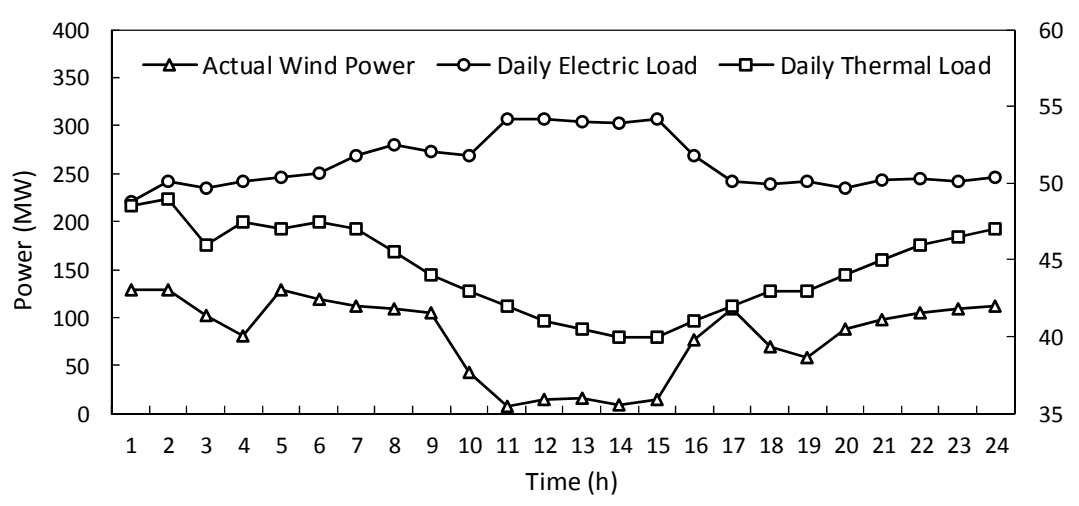

Figure 5. Daily profile for wind power, electric and thermal loads.

In order to verify the advantages of the proposed model in improving energy efficiency and energy saving and emission reduction, the day-ahead dispatch model will be simulated in two different operating modes which is conventional in Chinese northern heating periods. The system information with detailed data is provided in [18].

(A) Mode 1: Separate Generation of Heat and Power

In other words, the gas boilers supply the consumers' heat demand, the wind farm and thermal units supply the consumers' electricity demand. When the integrated network is added to the P2G link, hydrogen produced by the abandoned wind power is injected into the gas network by the hydrogen storage devices. The electric output, heating output and coal consumption should be recorded in two cases of the integrated system with P2G and without P2G. 
(B) Mode 2: Cogeneration

In other words, the CHPs supply the consumer' heat and electricity demands, the wind farm and thermal units supply the consumers' electricity demand with export when the local generation exceeds demand. The electric output, heating output and coal consumption also should be recorded in two cases of the integrated system with P2G and without P2G.

\subsection{Interpretation of Result}

The optimal output and the coal consumption of the model are solved by particle swarm algorithm in two modes. Programs are coded using MATLAB R2014a. Figure 6 shows the optimization results of Mode 1 with P2G. Figure 7 shows the optimization results of Mode 2 with P2G. The standard coal consumption of Mode1 and Mode 2 are shown in Figure 8 with the detailed data of the conversion coefficient of standard coal provided in Table 2.

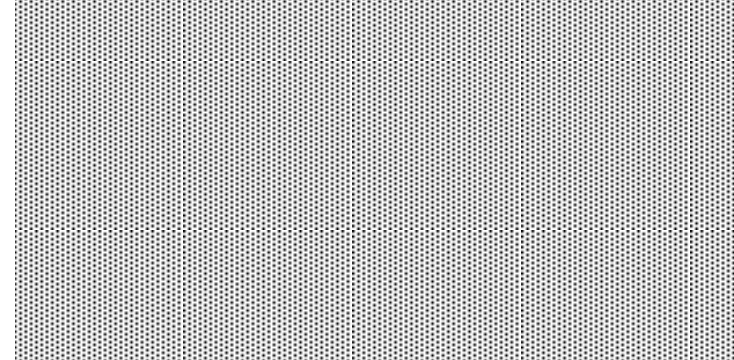

(a)

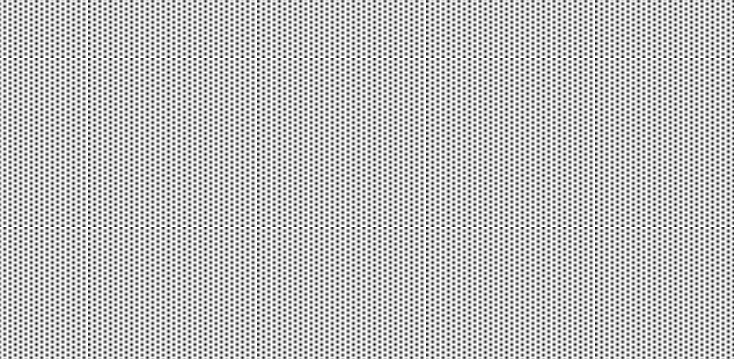

(b)

Figure 6. Profiles of Mode 1 with P2G: (a) power generation and (b) thermal generation.

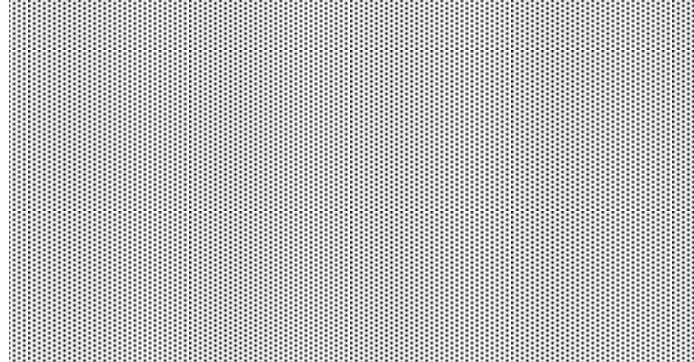

(a)

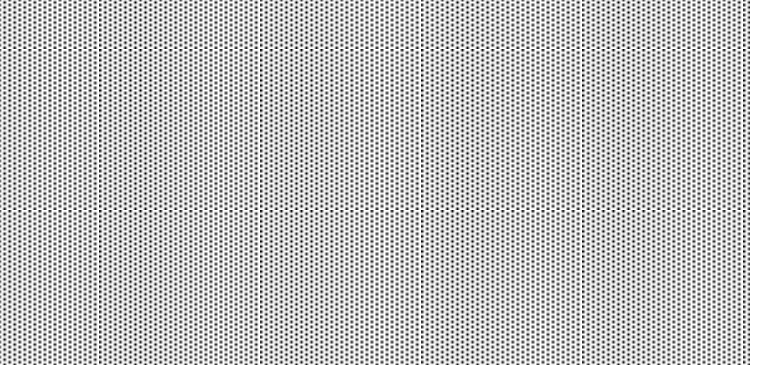

(b)

Figure 7. Profiles of Mode 2 with P2G: (a) power generation and (b) thermal generation.

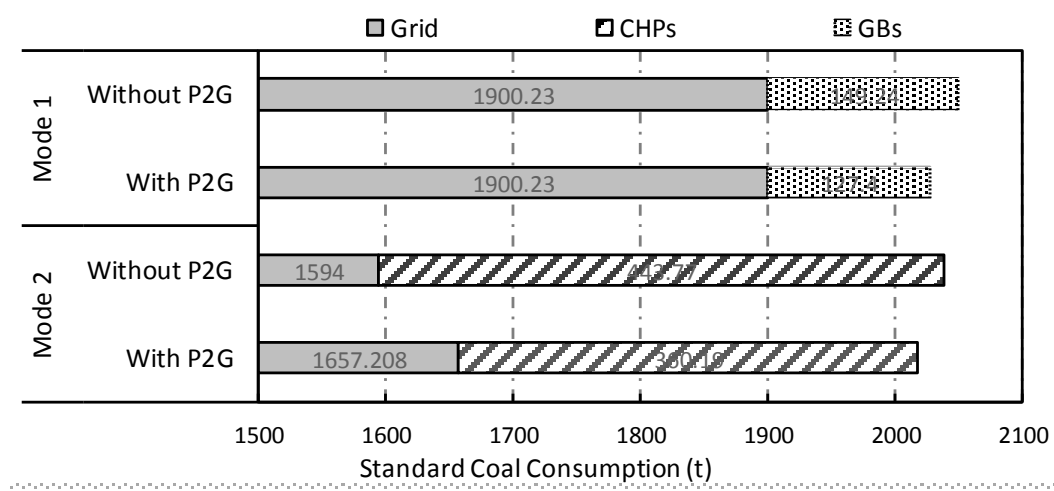

Figure 8. Standard coal consumption of two modes. 
Table 2. Standard coal consumption per kilowatt hour of each unit.

\begin{tabular}{cccc}
\hline$\lambda^{\mathrm{TU}}(\mathbf{k g} / \mathbf{k W})$ & $\underset{\mathrm{p}}{\mathrm{C} H P}(\mathbf{k g} / \mathbf{k W})$ & $\underset{\mathrm{h}}{\mathrm{CHP}}(\mathbf{k g} / \mathbf{k W})$ & $\lambda^{\mathrm{GB}}(\mathbf{k g} / \mathbf{k W})$ \\
\hline 0.404 & 0.379 & 0.113 & 0.142 \\
\hline
\end{tabular}

Based on the results of simulate, the integrated system with HCNG of two modes are analyzed in three aspects:

\section{(A) Heat Addition}

In the utilization of HCNG, the heat addition supplied by hydrogen of Mode 2 is slightly higher than Mode 1 in Figures $6 \mathrm{~b}$ and $7 \mathrm{~b}$. The reason for this is that the power generation of the CHPs cannot be dispatched when they are heating the users based on the principle of pricing electricity based on heat amount. At the same time, the grid capacity of wind power is reduced and the abandoned wind power is increased. Then, through the wind power electrolysis, the amount of hydrogen added to the gas network during each period of time is also increased.

\section{(B) Coal Consumption}

For the same mode, the coal consumption of the supply system with P2G is obviously lower in Figure 8 and Table 1. It is shown that the form of energy supply with HCNG is more energy efficient than the form of energy supply with the traditional gas network. The data released by the National Energy Administration shows that the Chinese electricity of abandoned wind electricity in the first half of 2015 was 17 billion 500 million KWh $[19,20]$. According to the related literature, the transformation efficiency of wind to hydrogen currently does not exceed $40 \%$ [21-25]. If all of the abandoned wind electricity is used to produce hydrogen, it will get 1 billion 958 million $\mathrm{m}^{3}$ of hydrogen, which can be converted to 5 billion 414 million $\mathrm{m}^{3}$ natural gas on an equal heat basis. At the same time, it will also reduce 10 million 210 thousand tons of the carbon dioxide of the combustion emission produced by the same volume of natural gas and save 65 million 740 thousand tons of the standard coal.

\section{(C) Energy Utilization}

For the traditional power and heat independent production system, the random fluctuation of wind power causes the grid capacity of wind power to be limited. For the combined power and heat system, the operation principle of the CHP units can also lead to the insufficient capacity of wind power. When the system is connected to the P2G process, almost all surplus wind power can be used to produce hydrogen for heating. Therefore, the efficiency of wind energy utilization is obviously improved.

\section{Conclusions}

A day-ahead dispatch model of electro-thermal integrated energy system with P2G Function is proposed in this paper. In the two common electro-thermal production modes, the operation mode of the proposed model is compared with the traditional mode supplied by single fuel gas. To cope with this complicated nonlinear program, the particle swarm optimization (PSO) algorithm is proposed to solve the problem. The simulation results show that: (a) the electro-thermal integrated energy system with P2G Function incorporates hydrogen as clean energy into existing gas supply networks, which produces high quality power and clean secondary energy and provides a new way to solve the problem of wind power consumption in the grid; (b) considering the electric and thermal energy constraints, the daily operation of the multi energy supply network is simulated and optimized in the model, which is proved to have better operational performance and flexibility; (c) an integrated energy grid with P2G function will save about 20 tons of standard coal per day and the abandoned wind rate can be regarded as 0 , which proves that the proposed day-ahead dispatch model can 
effectively improve the utilization efficiency of wind power, reduce the operating coal consumption of the coupling system and contribute to the realization of low-carbon energy supply.

Acknowledgments: The authors gratefully acknowledge the support of the National Natural Science Foundation of China (No. 51507028 and No. 51377017) and the "Thirteen five" Science and Technology Projects of The Education Department of Jilin Province (No. JJKH20170100KJ).

Author Contributions: Deyou Yang and Guowei Cai conceived and designed the experiments; Yufei Xi performed the experiments and analyzed the data, Deyou Yang and Yufei Xi wrote this paper.

Conflicts of Interest: The authors declare no conflict of interest.

\section{References}

1. Li, X.; Huang, Y.; Ma, S. Analysis on the influence factors of wind power accommodation. J. Power Energy Eng. 2015, 3, 162-169. [CrossRef]

2. Anne, S.B.; Machteld, B.; Ad, S. Impacts of large-scale intermittent renewable energy sources on electricity systems, and how these can be modeled. Renew. Sustain. Energy Rev. 2014, 33, 443-466.

3. Liu, Y.; Lund, B.; Mathiesen, V. Large-scale integration of wind power into the existing Chinese energy system. Energy 2011, 36, 4753-4760. [CrossRef]

4. Lu, J.; Zahedi, A.; Yang, C. Building the hydrogen economy in China: Drivers, resources and technologies. Renew. Sustain. Energy Rev. 2013, 23, 543-556. [CrossRef]

5. Harrison, K.W.; Kroposki, B.; Pink, C. Characterizing electrolyzer performance for use in wind energy applications. Presented at the IEEE American Wind Energy Association (AWEA) Wind power Annual Conference, Pittsburgh, PA, USA, 4-7 June 2006; pp. 7-8.

6. Nastasi, B.; Basso, G.L. Power-to-Gas integration in the transition towards future urban energy systems. Int. J. Hydrog. Energy 2017, 42, 23933-23951. [CrossRef]

7. Castellani, B.; Morini, E.; Bonamente, E.; Rossi, F. Experimental investigation and energy considerations on hydrate-based biogas upgrading with $\mathrm{CO}_{2}$ valorization. Biomass Bioenergy 2017, 105, 364-372. [CrossRef]

8. Marjanovic, B.; Bongers, T.; Lichtinghagen, J. Influence of Power-to-Gas-technology on unit commitment and power system operation. In Proceedings of the 2017 6th International Conference on Clean Electrical Power (ICCEP), Santa Margherita Ligure, Italy, 27-29 June 2017; Volume 6, pp. 536-540.

9. Clegg, S.; Mancarella, P. Integrated modeling and assessment of the operational impact of Power-to-Gas (P2G) on electrical and gas transmission networks. IEEE Trans. Sustain. Energy 2015, 6, 1234-1244. [CrossRef]

10. Li, C.; Goswami, D.Y.; Shapior, A. A new combined power and desalination system driven by low grade heat for concentrated brine. Energy 2012, 46, 582-595. [CrossRef]

11. Li, Z.G.; Wu, W.C. Combined heat and power dispatch considering pipeline energy storage of district heating network. IEEE Trans. Sustain. Energy 2016, 7, 12-22. [CrossRef]

12. European Union. Using the Existing Natural Gas System for Hydrogen; European Union: Brussels, Belgium, 2009.

13. Kippers, M.J; De, J.C.; Hermkens, R.G.M. International Gas Research Conference Proceedings; Curran Associates: North Miami Beach, FL, USA, 2011; pp. 32-37.

14. Mcphy Energy Role in French Power-to-Gas GRHYD programme. Fuel Cells Bull. 2014, 2, 9-10. Available online: http://www.sciencedirect.com/science/article/pii/S1464285914700549 (accessed on 28 February 2014).

15. Eberhat, R.C.; Shi, Y. Particle swarm optimization: Developments, applications and resources. Congr. Evolut. Comput. 2002, 1, 81-86.

16. Tyagi, G.; Pandit, M. Combined heat and power dispatch using Particle swarm optimization. In Proceedings of the 2012 IEEE Students' Conference on Electrical, Electronics and Computer Science (SCEECS), Bhopal, India, 1-2 March 2012; pp. 1-4.

17. Roy, R.K.; Paul, C.; Sultana, S. Oppositional teaching learning based optimization approach for combined heat and power dispatch. Int. J. Electr. Power Energy Syst. 2014, 57, 392-403. [CrossRef]

18. Saint, A.; Mancarella, P. Integrated electricity and heat active network management. In Proceedings of the IEEE Power Systems Computation Conference, Genoa, Italy, 20-24 June 2016; pp. 1-7.

19. Chen, X.; Kang, C.; Malley, M.O. Increasing the flexibility of combined heat and power for wind power integration in China: Modeling and implications. IEEE Trans. Power Syst. 2015, 30, 1848-1857. [CrossRef] 
20. Blarke, M. Towards an intermittency-friendly energy system. Appl. Energy 2012, 91, 349-365. [CrossRef]

21. Martinez, C.E.A.; Capudaer, T.; Mancarella, P. Flexible distributed multienergy generation system expansion planning under uncertainty. IEEE Trans. Smart Grid 2015, 19, 1-2. [CrossRef]

22. Dent, C.J.; Bialek, J.W.; Hobbs, B.F. Opportunity cost bidding by wind generators in forward markets: Analytical results. IEEE Trans. Power Syst. 2011, 26, 1600-1608. [CrossRef]

23. Ghorbani, N. Combined heat and power economic dispatch using exchange market algorithm. Int. J. Electr. Power Energy Syst. 2016, 82, 58-66. [CrossRef]

24. Yuan, R.; Ye, J.; Lei, J. Integrated Combined heat and system dispatch considering electrical and thermal energy storage. Energy 2016, 9, 474. [CrossRef]

25. The First Wind Power Hydrogen Project Settled in Hebei Province. Available online: http://www.ce.cn/ cysc/ny/dl/201508/20/t20150820_6274841.shtml (accessed on 20 August 2015).

(C) 2017 by the authors. Licensee MDPI, Basel, Switzerland. This article is an open access article distributed under the terms and conditions of the Creative Commons Attribution (CC BY) license (http:/ / creativecommons.org/licenses/by/4.0/). 